\title{
Concepçóes e uso do brincar na prática clínica de terapeutas ocupacionais
}

\author{
Maria Eduarda Diniz Fonsêca, Ângela Cristina Dornelas da Silva
}

Departamento de Terapia Ocupacional, Universidade Federal da Paraíba - UFPB, João Pessoa, PB, Brasil.

\begin{abstract}
Resumo: A terapia ocupacional tem como objeto de estudo o engajamento do indivíduo nas diversas áreas de ocupação e, neste sentido, o brincar se configura como uma área relevante para a população infantil. Este estudo objetivou verificar como os terapeutas ocupacionais que atuam no município de João Pessoa-PB percebem e utilizam o brincar na prática clínica. Para tanto, foi realizado um estudo exploratório, de abordagem quantitativa e qualitativa, com todos os terapeutas ocupacionais que tinham experiência no atendimento à criança e que estavam atuando no município de João Pessoa-PB, no período de junho a julho de 2014. Os dados foram coletados através de questionário elaborado com base nas concepções de Ferland e Blanche sobre o brincar, que englobou questões sobre o perfil dos participantes e suas percepções sobre o tema. Participaram da pesquisa 23 terapeutas ocupacionais, dentre os quais 69,6\% se graduaram na Região Nordeste, 43,5\% tinham título de especialista e 39,1\% tinham entre seis e dez anos de formação. O principal locus de aprendizado do brincar foi a graduação $(91,3 \%)$. O brincar para treinar habilidades é utilizado por $86,9 \%$ e, como fim em si mesmo, por 52,2\% dos pesquisados. Os teóricos da Psicologia são os que mais dão suporte à prática clínica dos pesquisados. Os resultados apontam para a necessidade de se aprofundarem as discussões sobre o brincar nos cursos de graduação em terapia ocupacional, valorizando as concepções e os modelos de intervenção próprios da profissão.
\end{abstract}

Palavras-chave: Terapia Ocupacional, Brincadeiras, Desenvolvimento Infantil, Prática Profissional.

\section{Conceptions and use of play in occupational therapists clinical practice}

\begin{abstract}
Occupational therapy aims to study the engagement of individuals in different areas of occupation and in this sense "playing" is configured as a relevant area for the pediatric population. We examined how occupational therapists working in the city of João Pessoa/PB perceive and use "playing" in the clinical practice. The participants took part in an exploratory study of quantitative and qualitative approach, with all occupational therapists who had experience in serving children and who were working in the city of João Pessoa / PB from June to July 2014. The data was collected through a questionnaire prepared based on Ferland and Blanche conceptions on "playing", and included questions about the participants profile and their perceptions on the topic. The group of participants consisted of 23 occupational therapists, among which $69.6 \%$ graduated in the Northeast, $43.5 \%$ were specialists and $39.1 \%$ had between 6 and 10 years of training. The main "playing" learning locus was graduation (91.3\%). "Playing" for skills training is used by $86.9 \%$ and as an end in itself for $52.2 \%$ of respondents. The theoretical psychologists compose the most supportive group towards the clinical practice of those surveyed. The results point to the need for further discussions on "playing" in undergraduate courses in Occupational Therapy, valuing the conceptions and characteristic intervention models commonly adopted in the profession.
\end{abstract}

Keywords: Occupational Therapy, Play, Child Development, Professional Practice.

Autor para correspondência: Ângela Cristina Dornelas da Silva, Departamento de Terapia Ocupacional, Universidade Federal da Paraíba, Campus I, s/n, Castelo Branco, CEP 58051-900, João Pessoa, PB, Brasil, e-mail: angeladornelas@yahoo.com.br

Recebido em Set. 19, 2014; $1^{\text {a }}$ Revisão em Nov. 18, 2014; $2^{\text {a }}$ Revisão em Maio 4, 2015; Aceito em Maio 23, 2015. 


\section{Introdução}

O brincar sempre esteve presente no cotidiano infantil. Sua importância é reconhecida e consta na Declaração Universal dos Direitos da Criança (aprovada na Assembleia Geral das Naçóes Unidas, em 1959), no artigo 70: "Toda criança terá direito a brincar e a divertir-se, cabendo à sociedade e às autoridades públicas garantir a ela o exercício pleno desse direito" (BRASIL, 1990, p. 4).

As crianças devem ser compreendidas como sujeitos articulados, para as quais o brincar, além de possuir um espaço privilegiado, também deve ser utilizado como estratégia de garantia de direitos e singularidades da infância, na medida em que é inserido em uma cultura (DEBORTOLI; LINHALES; VAGO, 2005).

Reis e Rezende (2007) referem que o brincar é uma das áreas de intervenção da terapia ocupacional, sendo importante considerar o papel de brincante e todos os fatores que influenciam de maneira positiva e/ou negativa no desenvolvimento global do indivíduo.

Para Ferland (2006), brincar é uma forma de dominar a realidade. A partir da brincadeira, a criança faz uma conexão entre o familiar e o desconhecido, e, aos poucos, ela aprisiona a realidade. Compreende-se que é muito mais que um comportamento, é uma atitude subjetiva, ou seja, brincar implica, além dos gestos e do brinquedo, um estado de espírito particular, uma predisposiçáo interna.

O brincar é uma atividade que se justifica por si mesma, um processo espontâneo e natural; ao brincar, a criança está em busca da descoberta, da indagação, da escolha e da recriação (SANTOS; MARQUES; PFEIFER, 2006).

Assim, o brincar é considerado um processo natural, que permite à criança desenvolver capacidades de adaptação e interação, as quais poderão ser transferidas para diversas situaçôes vivenciadas em seu cotidiano (FERLAND, 2006). O ambiente cotidiano da criança influencia diretamente no desenvolvimento de competências e habilidades, ou seja, a criança que brinca possui um repertório maior de experiências, além do brincar também se configurar como um importante fator de proteçáo para infância (POLETTO, 2005).

Segundo Emmel e Figueiredo (2011), o brincar se distingue de acordo com as fases do desenvolvimento. Durante a infância, as crianças desenvolvem e aprimoram vários aspectos, tais como: esquema corporal, lateralidade, coordenação motora global, coordenação motora fina, orientação espacial, orientação temporal e ritmo.

Para Piaget (1967), a criança constrói seu conhecimento a partir de experiências anteriores, mas, para que isso ocorra, suas estruturas mentais precisam estar prontas para fazer essa relação. Estas, por sua vez, irāo se organizar para construir um novo conceito ou ampliar um anteriormente construído. Mas é por meio dos jogos e brincadeiras que as crianças vão, aos poucos, elaborando conceitos. A característica ativa dos jogos e brincadeiras proporciona uma capacidade natural de aprendizagem para as crianças.

Do ponto de vista psicanalítico, Winnicott (1975) defende o brincar como um aspecto inerente à natureza humana, porém, existem pessoas que, em função de doenças, podem apresentar dificuldades em engajar-se na atividade do brincar. $\mathrm{O}$ autor destaca que o brincar é um facilitador do crescimento, um aliado para a saúde, além de promover relacionamentos grupais. Ele afirma, ainda, que, somente através do brincar, o indivíduo tem a oportunidade de ser criativo e de utilizar sua personalidade de forma integral. Porém, alerta que essa capacidade é instável, ou seja, sofrerá alteraçôes em função das condições pessoais e ambientais.

Neste sentido, Vectore (2003) ressalta que o espaço do brincar na vida da criança encontra-se ameaçado em função do mundo moderno, no qual houve alteraçôes no formato das famílias, além do ritmo acelerado da vida nas cidades. Salienta que é importante que os pais ou responsáveis criem estratégias para que as crianças de fato tenham a oportunidade de vivenciar o brincar em suas diferentes formas.

Segundo Hansen et al. (2007), existem vários motivos para que a criança brinque, dentre os quais podemos destacar o prazer que desfrutam quando estão brincando. Ressalta-se, entretanto, que a brincadeira é essencial ao desenvolvimento infantil, trazendo consigo benefícios imediatos e de longo prazo. Dentre os aspectos que são desenvolvidos a partir da brincadeira, estáo o cognitivo, o social, o afetivo e o físico.

No contexto da terapia ocupacional, o brincar é considerado como "[...] qualquer atividade espontânea e organizada que proporciona prazer, entretenimento e diversão [...]" (PARHAM; FAZIO, 1997, p. 252).

O brincar é muito utilizado na prática clínica da terapia ocupacional, no tratamento de crianças com deficiências, considerando-se que é a principal ocupação da infância e permeia todo o seu cotidiano. Esses profissionais devem focar-se nas habilidades e 
potencialidades da criança por meio da experiência do brincar, e buscar ambientes livres de barreiras sociais, físicas e culturais (ZAGUINI et al., 2011).

Pelosi e Nunes (2010) afirmam que, a princípio, os terapeutas ocupacionais faziam uso de recursos artesanais e adaptaçóes simples, como forma de facilitar a inclusão dos deficientes; mas, nos dias atuais, eles precisam ter um vasto conhecimento dos recursos de tecnologia assistiva, sendo estes diversos. Faz-se necessária uma atualização contínua na área, pois a todo instante surgem produtos inovadores no mercado.

Mas, para Varela e Oliver (2013), uma grande parcela da população náo possui acesso aos recursos de tecnologia assistiva produzidos pela comunidade científica e que são ofertados no mercado de produtos. Outras problemáticas referem-se aos fatos de que muitos produtos desenvolvidos nas universidades não estão no mercado e de que a produçáo de tecnologia assistiva no Brasil ainda é escassa, além da não isenção de impostos sobre os dispositivos importados. É preciso que o Terapeuta Ocupacional tenha criatividade para confeccionar equipamentos de tecnologia assistiva de baixo custo, quando assim for necessário, proporcionando, desta forma, um melhor desempenho ocupacional aos indivíduos que fazem uso desses dispositivos.

De acordo com Ferland (2006), existem duas correntes que tratam da utilização do brincar em terapia ocupacional. A primeira refere-se à utilização da atividade do brincar como um instrumento para despertar o interesse da criança em relação à terapia, podendo também estar associada a um determinado método de tratamento. A segunda retrata o brincar de uma forma mais ampla, na qual a utilização do brincar pelos terapeutas ocupacionais vai além da dimensão da atividade, ou seja, a criatividade e a imaginação fazem parte da terapia, possibilitando à criança uma gama maior de experiências. Os objetivos em longo prazo variam, mas normalmente possuem relação com a qualidade de vida e a autonomia funcional da criança.

Por outro lado, Blanche (2000) considera que o brincar na prática clínica do Terapeuta Ocupacional é utilizado com três ênfases. A primeira utiliza o brincar para motivar a participação da criança na terapia, instigar a criança a interagir com o ambiente e atingir os objetivos de tratamento. A segunda ênfase trata do brincar como um contexto para o desenvolvimento de capacidades adaptativas e, por isso, pretende o desenvolvimento de habilidades específicas e está relacionada a algum método de tratamento. A terceira ênfase utiliza o brincar como fim em si mesmo, buscando a experimentaçáo do prazer, do agir espontâneo e flexível para a criança.

Contudo, é a partir da formação profissional, do contato com teorias e métodos, e da experiência profissional que os terapeutas ocupacionais vão criando suas concepçóes sobre o brincar e modelam suas práticas com crianças, com base nas suas crenças.

Considerando-se que a terapia ocupacional estuda o engajamento do indivíduo nas diversas áreas de ocupação e que o brincar é uma área relevante para a população infantil, o presente estudo objetivou verificar como os terapeutas ocupacionais que atuam no município de João Pessoa-PB utilizam o brincar na prática clínica, identificando quais teorias permeiam a prática e qual é o locus de aprendizado sobre o brincar durante a formação em terapia ocupacional.

\section{Procedimentos metodológicos}

Trata-se de um estudo exploratório, de abordagem quantitativa e qualitativa, sobre a concepçáo e a utilização do brincar na prática clínica, realizado com todos os terapeutas ocupacionais que estavam atuando no Município de João Pessoa-PB, no período de junho a julho de 2014, e que tinham experiência no atendimento à criança. Os terapeutas ocupacionais foram localizados através da delegacia do Conselho Regional de Fisioterapia e Terapia Ocupacional - Crefito 1, em João Pessoa. O Crefito forneceu um mapeamento das instituiçóes que tinham serviço de terapia ocupacional. De posse deste mapeamento, os pesquisadores entraram em contato com os terapeutas ocupacionais e aqueles que preenchiam os critérios de inclusão para participar da pesquisa foram convidados. Mediante a aceitação da participação no estudo e da assinatura do Termo de Consentimento Livre e Esclarecido, os terapeutas recebiam um questionário e eram marcadas as datas para devoluçáo dos mesmos preenchidos.

O questionário semiestruturado foi elaborado especificamente para este estudo, baseado nas concepçôes de Ferland (2006) e Blanche (2000) em relação ao brincar na clínica da terapia ocupacional, e englobou questôes de natureza demográfica e sobre a formação continuada, os teóricos que dáo suporte ao uso do brincar na prática e como os terapeutas utilizam o brincar, além de um espaço para que os profissionais pudessem expressar suas opinióes sobre o tema.

Os resultados foram analisados por estatística descritiva através de frequência absoluta e relativa (componente quantitativo). As opinióes dos terapeutas ocupacionais sobre o tema foram analisadas a partir 
da técnica de análise de conteúdo (componente qualitativo).

A pesquisa seguiu os critérios e exigências

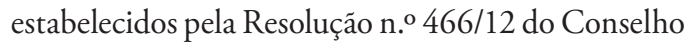
Nacional de Saúde (CNS) e foi aprovada pelo Comité de Ética em Pesquisa (CEP) do Centro de Ciências da Saúde (CCS) da Universidade Federal da Paraíba (UFPB).

\section{Resultados e discussão}

Foram identificados 24 terapeutas ocupacionais que tinham experiência no atendimento à criança $\mathrm{e}$ que estavam atuando no município de Joáo Pessoa, durante o estudo. Entretanto, a amostra se constituiu de 23 terapeutas, porque um deles não devolveu o questionário respondido. Dos 23 terapeutas, dois eram do sexo masculino $(8,7 \%)$ e 21 do sexo feminino (91,3\%).

A Tabela 1 apresenta as características da amostra quanto à formação profissional, a instituição de trabalho e o locus de aprendizado sobre o brincar.
Observa-se que a maioria dos terapeutas concluiu a Graduação na Região Nordeste (69,6\%), trabalha em Instituição de Ensino Superior (43,5\%), tem como maior nível de escolaridade a Especialização $(43,5 \%)$ e tem entre seis e dez anos de profissão $(39,1 \%)$. Vale salientar que no caso de o terapeuta possuir dois vínculos empregatícios, foi considerada a instituição em que o mesmo trabalha com criança.

Em relação ao locus de aprendizado do brincar, a maioria entrou em contato com o tema durante a Graduação em terapia ocupacional $(91,3 \%)$ e um terapeuta $(4,3 \%)$ declarou ter tido contato com o tema apenas através de livros. O brincar foi estudado em Cursos de Aperfeiçoamento por sete terapeutas $(30,4 \%)$ e em pós-graduaçôes lato e stricto sensu por oito terapeutas $(34,8 \%)$.

A Tabela 2 apresenta as frequências quanto aos objetivos da utilização do brincar pelos terapeutas ocupacionais durante o processo terapêutico.

Observa-se que o uso mais frequente do brincar nas terapias é como meio para treinar habilidades $(86,9 \%)$, seguido do uso para facilitar o vínculo terapeuta-paciente $(82,6 \%)$. O uso do brincar como

Tabela 1. Características da formação de 23 terapeutas ocupacionais que atuam em João Pessoa-PB, 2014.

\begin{tabular}{llccc}
\hline & Variáveis & Frequência & $\mathbf{( \% )}$ & N \\
\hline Região de formação & Nordeste & 16 & 69,6 & 23 \\
& Sudeste & 7 & 30,4 & \\
Característica da instituição & Serviço de Reabilitação & 9 & 39,1 & 23 \\
em que trabalha & Instituição de Ensino Superior & 10 & 43,5 & \\
& Hospital & 2 & 8,7 & \\
\multirow{4}{*}{ Nível de escolaridade } & Centro de Atenção Psicossocial & 2 & 8,7 & \\
& Graduação & 2 & 8,7 & 23 \\
& Aperfeiçoamento & 1 & 4,3 & \\
Especialização & 10 & 43,5 & \\
Tempo de graduado & Mestrado & 9 & 39,1 & \\
& Doutorado & 1 & 4,3 & \\
0 a 2 anos & 2 & 8,7 & 23 \\
Estudou sobre o brincar na Graduação & 5 & 21,7 & \\
Estudou sobre o brincar em Curso de Aperfeiçoamento & 9 & 39,1 & \\
Estudou sobre o brincar em curso de Pós-Graduação & 7 & 30,4 & \\
Estudou sobre o brincar apenas através de livros & 21 & 91,3 & 23 \\
\hline
\end{tabular}

Tabela 2. Objetivos da utilização do brincar para 23 terapeutas ocupacionais que atuam em João Pessoa-PB, 2014

\begin{tabular}{lccc}
\hline \multicolumn{1}{c}{ VARIÁVEIS } & Frequência & $\mathbf{( \% )}$ & $\mathbf{N}$ \\
\hline Utiliza o brincar para facilitar o vínculo & 19 & 82,6 & 23 \\
Utiliza o brincar como fim em si mesmo & 12 & 52,2 & 23 \\
Utiliza o brincar como meio para treinar habilidades & 20 & 86,9 & 23 \\
\hline
\end{tabular}


fim em si mesmo foi referido por pouco mais da metade dos terapeutas ocupacionais $(52,2 \%)$.

A Tabela 3 apresenta os teóricos mais citados pelos terapeutas ocupacionais como aqueles que dâo suporte às suas práticas clínicas.

Observa-se que, dentre os teóricos do brincar, os mais utilizados pelos terapeutas na prática clínica são Piaget (65,2\%), Winnicott (43,5\%) e Vygotsky $(34,8 \%)$, e que, dentre os específicos da terapia ocupacional, são Ferland (47,8\%) e Takatori (26,1\%).

A Tabela 4 apresenta os momentos da vida da criança para os quais os terapeutas ocupacionais referiram fazer orientaçóes para o brincar que não fosse o momento da terapia.

Observa-se que os terapeutas ocupacionais orientam com maior frequência o brincar no cotidiano da criança em casa $(56,5 \%)$ e durante as atividades de lazer $(52,1 \%)$.
Quanto aos relatos dos profissionais sobre os benefícios que a utilização do brincar traz para a criança e sua família, a Tabela 5 apresenta as categorias que emergiram e as frequências com que elas apareceram nos discursos dos terapeutas.

Observa-se que o benefício mais citado em relaçáo ao uso do brincar é promover o desenvolvimento de habilidades sociais $(91,3 \%)$, seguido de melhorar o desenvolvimento neuropsicomotor $(78,3 \%)$, que inclui melhorar o desenvolvimento da motricidade e/ou da linguagem e/ou da cognição e/ou da sensopercepção.

Em relação às opinióes sobre o brincar e a terapia ocupacional, 13 dos pesquisados fizeram comentários, surgindo as seguintes ideias: "[...] o brincar recebe pouca importância da comunidade científica [...]”; "[...] a utilizaçáo do brincar na terapia ocupacional tem como foco melhorar o desenvolvimento infantil [...]"; "[...] a graduação em terapia ocupacional precisa investir nas teorias da própria profissão sobre o

Tabela 3. Teóricos que dão suporte para o uso do brincar na prática clínica de 23 Terapeutas Ocupacionais que atuam em João Pessoa-PB, 2014.

\begin{tabular}{lccc}
\hline \multicolumn{1}{c}{ Teóricos } & Frequência & $\mathbf{( \% )}$ & $\mathbf{N}$ \\
\hline Jean Piaget & 15 & 65,2 & 23 \\
Donald Winnicott & 10 & 43,5 & 23 \\
Lev Vygotsky & 8 & 34,8 & 23 \\
Sigmund Freud & 3 & 13,0 & 23 \\
Arnold Gesell & 3 & 13,0 & 23 \\
Francine Ferland & 11 & 47,8 & 23 \\
Marisa Takatori & 6 & 26,1 & 23 \\
Linda Florey & 3 & 13,0 & 23 \\
Nancy Takata & 3 & 13,0 & 23 \\
\hline
\end{tabular}

Tabela 4. Momentos da vida da criança para os quais os Terapeutas Ocupacionais do município de João Pessoa-PB orientam o brincar, 2014.

\begin{tabular}{lccc}
\hline \multicolumn{1}{c}{ Momentos } & Frequência & $\mathbf{( \% )}$ & $\mathbf{N}$ \\
\hline Em Casa & 13 & 56,5 & 23 \\
Durante o Lazer & 12 & 52,1 & 23 \\
Todos os espaços de vida da criança & 8 & 34,7 & 23 \\
Na Escola & 8 & 34,7 & 23 \\
Convívio Social & 3 & 13,0 & 23 \\
Durante a realização das AVD & 1 & 4,3 & 23 \\
\hline
\end{tabular}

AVD $=$ Atividades da Vida Diária.

Tabela 5. Benefícios do uso do brincar para a criança e a família de acordo com a percepção de 23 Terapeutas Ocupacionais, João Pessoa-PB, 2014.

\begin{tabular}{lccc}
\hline \multicolumn{1}{c}{ Benefícios } & Frequência & $\mathbf{( \% )}$ & N \\
\hline Promove o engajamento em ocupações (AVD, Educação e Brincar) & 11 & 47,8 & 23 \\
Melhora o desenvolvimento neuropsicomotor & 18 & 78,3 & 23 \\
Facilita o processo terapêutico & 04 & 17,4 & 23 \\
Promove o desenvolvimento de habilidades sociais & 21 & 91,3 & 23 \\
Promove o desenvolvimento emocional e da personalidade & 10 & 43,5 & 23 \\
\hline
\end{tabular}


brincar [...]"; "[...] a utilização do brincar como meio de alcançar objetivos precisa ser revisto pelos terapeutas ocupacionais [...]".

O perfil dos terapeutas ocupacionais que atuam em João Pessoa e têm experiência no atendimento à criança é ter sido formado em outros Estados do Nordeste, trabalhar em Instituição de Ensino Superior, ter entre seis e dez anos de graduado, e possuir título de especialista. Isto sugere que os terapeutas que atuam em João Pessoa são experientes na profissáo e que os resultados do estudo podem ser o reflexo da formação em terapia ocupacional, principalmente, na Região Nordeste.

A maior parte dos entrevistados trabalha em Instituição de Ensino Superior, principalmente como professor, e todos se formaram em outros Estados brasileiros, o que se explica pelo fato de que só recentemente foi implantado o único Curso de terapia ocupacional do Estado.

Em relação ao locus de aprendizado sobre o brincar, o Curso de Graduaçáo em terapia ocupacional apareceu como o espaço durante a formação profissional que mais propicia este aprendizado. Por outro lado, os teóricos que mais norteiam as práticas dos terapeutas advêm de outras áreas de conhecimento, como a Psicologia, sugerindo que, na Graduação, foram pouco exploradas as teorias próprias da terapia ocupacional quanto ao brincar. Este fato é ilustrado nos discursos dos pesquisados quando escrevem:

Essa pesquisa desperta sobre a necessidade da melhor capacitação sobre as teorias do brincar, na graduação, para que nossa atuação seja melhor embasada. (pesquisado 16)

Pouca importância é dada pela comunidade acadêmica a integração do brincar não somente como ocupação, mas instruida nos processos terapêuticos e demais situaçôes que a criança tenha participação no cotidiano e nos serviços de saúde. (pesquisado 8)

Estes resultados são semelhantes aos encontrados por Brunello et al. (2013), em estudo realizado na cidade Sáo Paulo, que identificou como principais referenciais teórico-metodológicos utilizados pelas terapeutas ocupacionais, para fundamentar a prática em relação ao brincar, a Teoria Winnicottiana, seguida da Teoria do Desenvolvimento de Piaget e da Teoria Construtivista e Histórico-Social de Vygotskyi.

Quanto ao uso do brincar nas terapias, este é utilizado na maioria das vezes como meio para alcançar objetivos do tratamento e não como um dos objetivos do tratamento. Grande parte dos pesquisados utiliza o brincar para treinar habilidades e para melhorar o vínculo terapêutico.

Esta concepção é reafirmada quando os profissionais são questionados a respeito dos benefícios do brincar para a vida da criança e da sua família. A maioria dos discursos converge para o uso do brincar como forma de promover o desenvolvimento de habilidades importantes para o desenvolvimento infantil. Os discursos que seguem corroboram esta ideia:

Dentro da minha prática clinica, o brincar, em todas as áreas em que atuo é fundamental para se conseguir atingir os objetivos traçados para cada paciente. No primeiro momento com a atuação do terapeutalpaciente o brincar é o meio de se conseguir o elo de interaçáo para chegarmos a uma boa evolução. (pesquisado 18)

O brincar é uma ferramenta inerente ao processo da TO com crianças altamente potente. Através dela observamos limitaçóes e potencialidades, como também suas variaçóes irão permitir uma estimulação oportuna para que a criança atinja o desenvolvimento ótimo. (pesquisado 10)

Para crianças com alteração de comportamento, o oferecimento de variados brinquedos, materiais e instrumentos lúdicos, favorecem a criação de vinculo terapêutico "abrindo caminhos" para que o efetivo tratamento ocorra. Um simples objeto pode ter função lúdica suficiente para estimular contato, interesse pelo meio e sociabilidade; por isso o TO precisa ser perspicaz, criativo e incentivador. (pesquisado 21)

Tais discursos parecem ser o reflexo do aperfeiçoamento dos profissionais em metodologias e técnicas de tratamento, para as quais o brincar é utilizado como meio para alcançar objetivos. De acordo com Primeau (2011, p. 653):

a brincadeira e o lazer como meios são frequentemente utilizados para abordar comprometimentos em estruturas e funçóes orgânicas dos clientes e as limitações em suas habilidades de desempenho. Utilizando a abordagem de tratamento/restaurar [...], os profissionais engajam seus clientes nas atividades de brincadeira e lazer que se destinam a facilitar aquisiçẫo de suas metas de tratamento relacionadas a esses comprometimentos e limitações.

Um estudo conduzido nos Estados Unidos da América, nos anos 1990, corrobora estes achados, pois demonstrou que $100 \%$ dos terapeutas ocupacionais que trabalhavam com crianças pré-escolares utilizavam a brincadeira como uma modalidade 
terapêutica para melhorar os resultados referentes às habilidades motoras, sensoriais ou psicossociais (COUCH; DEITZ; KANNY, 1998).

O estudo de Silva e Pontes (2013), realizado com terapeutas ocupacionais no Sudeste do Brasil, também evidenciou que a maior parte dos entrevistados utiliza o brincar como o facilitador do processo terapêutico e com base nas premissas de métodos de tratamento como a Terapia de Integração Sensorial e o Método Neuroevolutivo Bobath.

Contrapondo-se a esta percepção sobre o uso do brincar, Takatori (2003) ressalta que a preocupação do Terapeuta Ocupacional deve ser em relação à organização das atividades do sujeito no cotidiano, independentemente das dificuldades enfrentadas por ele, e que o brincar não deve ser uma motivação no processo terapêutico, nem tampouco um meio para desenvolver habilidades motoras. O brincar é uma forma de a criança estar no mundo, expressar-se e se desenvolver.

Neste mesmo sentido, Ferland (2006) defende a utilização do Modelo Lúdico na prática da terapia ocupacional, no qual se destaca a riqueza extraordinária do potencial terapêutico do brincar e que se propóe abordar a criança em um domínio que lhe é próprio, a saber, o brincar.

Apesar de Ferland e Takatori serem os principais teóricos da terapia ocupacional citados como referência para os pesquisados, observa-se que, na prática clínica destes terapeutas, predomina o uso do brincar tal como os métodos especializados de tratamento preconizam.

Sobre o assunto, Rezende (2008, p. 42) destaca que:

[...] se a terapia ocupacional vai continuar alocando o brincar como sua área de abrangência, assim como as tarefas de autocuidado e escolar, os profissionais precisam encontrar caminhos mais efetivos direcionados ao comportamento de brincar como sua prática, incluindo bons instrumentos de avaliaçáo e a prática baseada em evidências.

As inquietaçóes quanto ao uso do brincar apenas como meio de tratamento pelos terapeutas ocupacionais também foram evidenciadas nas opinióes de alguns pesquisados:

Acho extremamente relevante esta pesquisa, fico muito feliz que ela aconteça. A questão do "uso" do brincar como um meio para se conseguir determinado acontecimento ou habilidade sempre me inquietou. Não que isso também não seja benéfico, mas muitas vezes é utilizado para justificar nossa prática perante a ciência hegemônica, em detrimento de uma questão extremamente essencial que é a do brincar como um fim em si mesmo, pelo simples fato de ser a atividade a partir do qual a criança se a apropria do mundo. (pesquisado 17)

\begin{abstract}
Acho que muitas vezes os terapeutas ocupacionais lidam apenas com o "brincar" como meio. Coloco o brincar entre aspas porque muitas vezes a criança não está brincando! O terapeuta que pensa que aquilo, aquele ato ou técnica, ou aquele objeto estão proporcionando o brincar, mas não estão muitas vezes. Acho que temos que dar mais valor ao brincar como fim em si mesmo e como meta de terapia; afinal de contas, o brincar é sim a principal ocupação da criança e, brincando, a criança desenvolve. (pesquisado 06)
\end{abstract}

Acredito que a terapia ocupacional tem um diferencial único na compreensão do brincar que deve ser assumido nas intervençóes e nas reflexóes multidisciplinares sobre o tema. Ainda sobre este tema considero importante investigar sobre como os profissionais da terapia ocupacional têm avaliado o brincar de suas crianças em beneficio do tratamento dessas. (pesquisado 01)

Nestas perspectivas, Blanche (2000) ressalta que o uso do brincar na intervenção e na vida da criança demanda conhecimento das características e da essência do brincar. Alguns aspectos que devem ser levados em consideração são: a espontaneidade ao iniciar, modificar ou finalizar uma atividade; a motivação intrínseca; a habilidade de suspender a realidade; o aproveitamento do processo; a participação ativa, e o despertar enfatizado.

Ressalta também que, normalmente, a "espontaneidade" é inibida em função das limitaçôes físicas; porém, no momento em que o terapeuta ocupacional avalia a criança e a coloca em um ambiente convidativo, ela se sente encorajada a brincar. A espontaneidade pode ser utilizada na sessão de tratamento, tornando-se possível de ser alcançada, na medida em que o terapeuta não age de forma direta, fornece atividades flexíveis, em que as regras possam ser adaptadas ou modificadas (BLANCHE, 2000).

No contexto da Ciência Ocupacional, Humphry (2011, p.23) refere que a terapia ocupacional deve "[...] deslocar o foco do desenvolvimento das capacidades de desempenho de um indivíduo para o desenvolvimento das ocupaçóes em um contexto social [...]" e é assim que o brincar deve ser evidenciado pelos terapeutas ocupacionais.

Entretanto, independentemente da concepção e do modo de utilizar o brincar adotados pelos terapeutas ocupacionais pesquisados, todos demonstraram ter consciência da importância do brincar, ao 
relatarem que fazem recomendaçóes para que a criança experimente o brincar em outros espaços de suas vidas.

Contudo, os terapeutas ocupacionais também devem ter em mente que a promoção do brincar para a população infantil é uma ação de saúde, que contribui náo só para o desenvolvimento infantil, mas também para a ressignificaçáo do modelo de cuidado das crianças (MITRE; GOMES, 2004).

\section{Conclusão}

Os achados deste estudo apontam para a necessidade de se aprofundarem as discussōes sobre o brincar nos cursos de Graduação em terapia ocupacional, valorizando as concepçôes e os modelos de intervenção próprios da profissão. A ampliaçấo dos debates a respeito da utilização do brincar na prática clínica também deve fazer parte da educação continuada e dos eventos científicos da terapia ocupacional.

A superação do modelo de utilização do brincar apenas como meio de alcançar os objetivos do tratamento parece ser promissora em trazer maiores benefícios para as crianças assistidas pela terapia ocupacional e suas respectivas famílias, além de possibilitar o incremento de pesquisas que revelem o potencial que o brincar tem para a promoção do bem-estar infantil.

\section{Referências}

BLANCHE, E. I. Fazer junto com- não fazer para: a recreação e as crianças portadoras de paralisia cerebral. In: PARHAM, L. D.; FAZIO, L. S. A recreação na terapia ocupacional pediátrica. São Paulo: Santos, 2000. p. 202-218.

BRASIL. Presidência da República. Subchefia para Assuntos Jurídicos. Lei no 8.069, de 13 de julho de 1990. Dispóe sobre o Estatuto da Criança e do Adolescente e dá outras providências. Diário Oficial da República Federativa do Brasil, Poder Executivo, Brasília, DF, 16 jul.1990.

BRUNELLO, M. I. B.; MIETO, F. S. R.; SILVA, C. D. Procedimentos de avaliaçáo da qualidade do brincar na prática da terapia ocupacional: um estudo exploratório. Revista de Terapia Ocupacional da Universidade de São Paulo, São Paulo, v. 10, n. 2, p. 95-102, 2013.

COUCH, K. J.; DEITZ, J. C.; KANNY, E. M. The role of play in pediatric occupational therapy. The American Journal of Occupational Therapy: Official Publication of the American Occupational Therapy Association, Montgomery, v. 52, n. 2, p. 111-117, 1998. http://dx.doi. org/10.5014/ajot.52.2.111. PMid:9494631.

DEBORTOLI, J. A. O.; LINHALES, M. A.; VAGO, T. M. Da articulaçáo entre a formaçáo dos docentes de Educaçáo Física e a formação dos profissionais de educa- ção infantil para a ação - reflexão da prática. In: BORGES, C.; DESBIENS, J. F. Saber, formar e intervir: para uma Educação Física em mudança. Campinas: Autores Associados, 2005. p. 191-211.

EMMEL, M. L. G.; FIGUEIREDO, M. O. O brincar, o desenvolvimento psicomotor e a aprendizagem. In: ENCONTRO DA ASSOCIAÇÃO BRASILEIRA DE PESQUISADORES EM EDUCAÇÃO ESPECIAL, 6., 2015, Londrina, Anais...Londrina: ABPEE, 2011. p. 3963-3875. Disponível em: <http://www.uel. br/eventos/congressomultidisciplinar/pages/arquivos/ anais/2011/brincar/363-2011.pdf.> Acesso em: 15 jan. 2015.

FERLAND, F. $O$ modelo lúdico: o brincar, a criança com deficiência física e a terapia ocupacional. São Paulo: Editora Roca, 2006.

HANSEN, J. et al. O brincar e suas implicaçóes para o desenvolvimento infantil a partir da psicologia evolucionista. Revista Brasileira de Crescimento e Desenvolvimento Humano, São Paulo, v. 17, n. 2, p. 133-143, 2007.

HUMPHRY, R. Ocupaçăo e desenvolvimento: uma perspectiva contextual. In: CREPAU, E. B.; COHN, E.; SCHELL, B. A. B. Willard \& Spackman - terapia ocupacional. Rio de Janeiro: Guanabara Koogan, 2011. p. 22-32.

MITRE, R. M. A.; GOMES, R. A promoçáo do brincar no contexto da hospitalização infantil como açáo de saúde. Ciencia \& Saúde Coletiva, Rio de Janeiro, v. 9, n. 1, p. 147-154, 2004. http://dx.doi.org/10.1590/S141381232004000100015 .

PARHAM, L. D.; FAZIO, L. S. Play in occupational therapy for children. St. Louis: Mosby, 1997.

PELOSI, M. B.; NUNES, L. R. O. P. Os terapeutas ocupacionais das unidades de saúde do município do Rio de Janeiro e suas ações na área de tecnologia assistiva. Revista Teias, Rio de Janeiro, v. 11, n. 23, p. 149-162, 2010.

PIAGET, J. Psicologia da inteligência. Rio de Janeiro: Zahar Editores, 1967.

POLETTO, R. C. A ludicidade da criança e sua relaçấo com o contexto familiar. Psicologia em Estudo, Maringá, v. 10 , n. 1 , p. $67-75,2005$. http://dx.doi.org/10.1590/ S1413-73722005000100009.

PRIMEAU, L. A. Brincadeira e lazer. In: CREPAU, E. B.; COHN, E.; SCHELL, B. A. B. Willard \& Spackman - terapia ocupacional. Rio de Janeiro: Guanabara Koogan, 2011. p. 644-660.

REIS, N. M. M.; REZENDE, M. B. Adaptaçôes para o brincar. In: CAVALCANTI, A.; GALVÃO, C. Terapia ocupacional: fundamentação e prática. Rio de Janeiro: Guanabara Koogan, 2007. p. 338-343.

REZENDE, M. B. O brincar e a intervenção da terapia ocupacional. In: DRUMOND, A. F.; REZENDE, M. B. Intervençôes da terapia ocupacional. Belo Horizonte: Editora UFMG, 2008. p. 25-44. 
SANTOS, A. C.; MARQUES, E. M.; PFEIFER, L. I. A brinquedoteca sob a visão da terapia ocupacional: diferentes contextos. Cadernos de Terapia Ocupacional da UFSCar, São Carlos, v. 14, n. 2, p. 91-102, 2006.

SILVA, C. C. B.; PONTES, F. V. A utilização do brincar nas práticas de terapeutas ocupacionais da Baixada Santista. Revista de Terapia Ocupacional da Universidade de São Paulo, São Paulo, v. 24, n. 3, p. 226-232, 2013. http://dx.doi.org/10.11606/issn.2238-6149. v24i3p226-232.

TAKATORI, M. O brincar no cotidiano da criança com deficiência física: reflexões sobre a clínica da terapia ocupacional. São Paulo: Atheneu, 2003.

VARELA, R. C. B.; OLIVER, F. C. A utilização de Tecnologia Assistiva na vida cotidiana de crianças com defi- ciência. Ciência \& Saúde Coletiva, Rio de Janeiro, v. 18, n. 6, p. 1773-1784, 2013. http://dx.doi.org/10.1590/ S1413-81232013001400028. PMid:23752543.

VECTORE, C. O brincar e a intervenção mediacional na formação continuada de professores de educação infantil. Psicologia USP, São Paulo, v. 14, n. 3, p. 105-131, 2003. http://dx.doi.org/10.1590/S010365642003000300010 .

WINNICOTT, D. W. O Brincar e a realidade. Rio de Janeiro: Imago Editora, 1975.

ZAGUINI, C. G. S. et al. Avaliação do comportamento lúdico da criança com paralisia cerebral e da percepção de seus cuidadores. Acta Fisiatrica, São Paulo, v. 18, n. 4, p. 187-191, 2011. http://dx.doi.org/10.5935/01047795.20110004 .

\section{Contribuição dos Autores}

Maria Eduarda Diniz Fonsêca: Concepção do texto, organização das fontes e redação do texto. Ângela Cristina Dornelas da Silva: Análise dos resultados, redação e revisão do texto.

Os autores aprovaram a versão final do texto. 